\title{
Discovery of the Femur and the Humerus of Sinanthropus Pekinensis
}

\author{
By Prof. Franz Weidenreich \\ Cenozoic Research Laboratory, Peiping Union Medical College
}

\section{THE FEMUR}

$\mathrm{A}^{\mathrm{N}}$ MONG the extensive material recovered from Locality 1 at Choukoutien during the excavations of 1936-37 and afterwards prepared in the Laboratory, Dr. W. C. Pei discovered two fragments

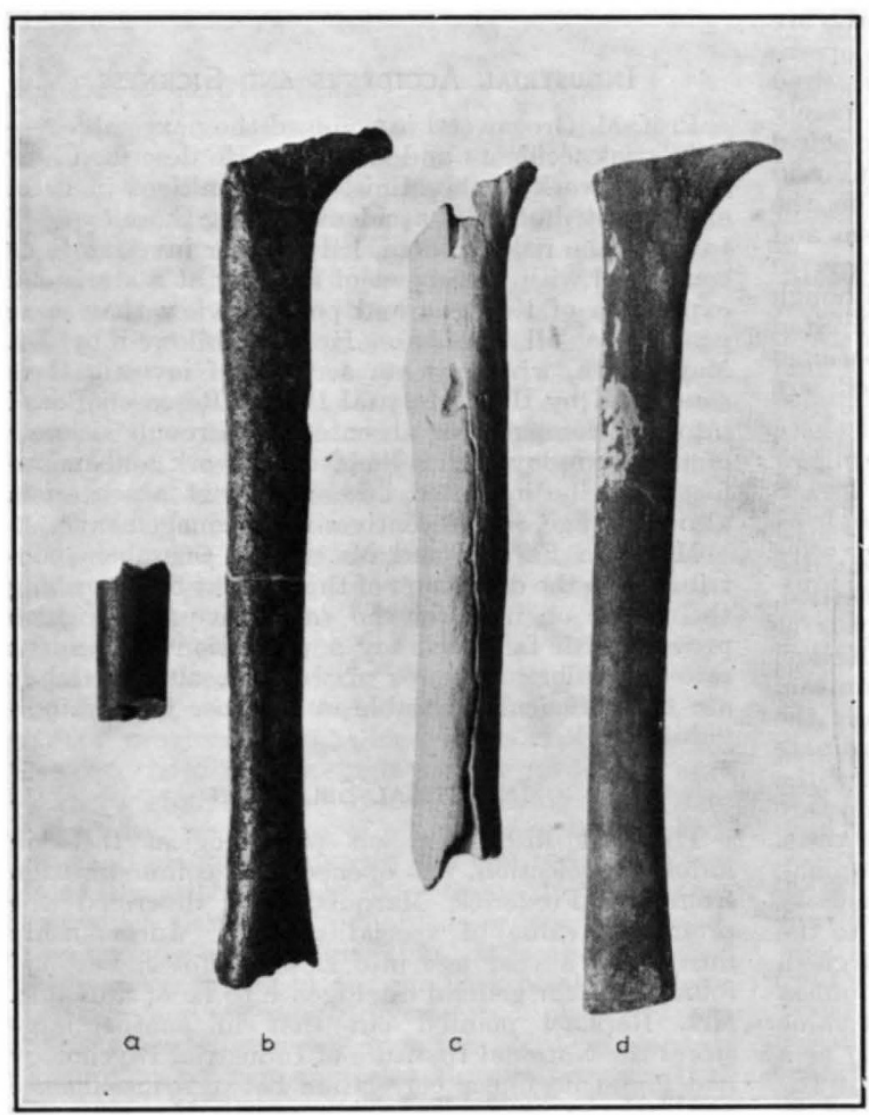

Fig. 1 .

COMPARATIVE vIEW OF THE ANTERIOR SURFACE OF FEMORA: (a) Sinanthropus FEMUR $J$; (b) Sinanthropus FEMUR $M$; (c) THE FRAGMENT OF A FEMUR OF THE MAN OF WEIMAREHRINGSDORF (NEANDERTHAL GROUP) WHICH HAS NOT BEEN DESCRIBED (CAST); (d) FEMUR OF A FEMALE INDIVIDUAL OF RECENT MAN (MORAVIAN) - UPPER AND LOWER PARTS REMOVEDTO CONFORM TO THE SIZE OF_THE Sinanthropus FEMUR $M .(\times 3 / 10$. adult female skull described as Skull $J$ in 1937, and four skull fragments of a very young child recently found among the prepared material. Femur fragment II comes from Level 26 of the western area of the cave, from which we have two fragments of one adult male and one adult female mandible as yet not described. Femur specimen I will be known as Femur $J$ and specimen II as Femur $M$.

Femur $J$ (Figs. 1 and 2, $a$ ) represent a portion of the middle of the shaft and measures $58 \mathrm{~mm}$. The bone is completely fossilized and burnt, as is evident by the marked blackening of the entire anterior and medial surface and on the part where it was broken off. That we are actually dealing with a human femur is demonstrated by the form and size, but particularly by the existence of a rather distinct pilaster (Broca) which occupies the middle of the posterior surface and bears a well-developed linea aspera dividing into characteristic medial and lateral lips toward the end of the fragment.

Femur $M$ (Figs. 1 and $2, b$ ) embraces almost the entire diaphysis. Its length is $312 \mathrm{~mm}$. At the upper end, the head and trochanters are broken off, whereas the entire inferior border of the neck is preserved. The lower end is likewise missing but the upper end of the suprapatellar fossa is still recognizable. This femur also is strongly fossilized. Certain parts of the surface are weathered but all the characteristic features are sufficiently preserved to permit a criterion. Like specimen $J$, this piece shows a distinct pilaster running along the middle of the posterior surface and bears a linea aspera consisting of two lips. Its relative completeness, however, makes it possible to determine the general form and the peculiarities of the shaft. Estimated on the basis of the length of the preserved portion of the femur, the total length may have been $400 \mathrm{~mm}$.

The femur of Sinanthropus has, in common with that of recent man (Figs. 1 and 2,d), the general shape and the formation of a pilaster with a two-lipped linea aspera. In addition, there is a suprapatellar fossa, its lateral border being formed by a distinct ridge which gradually disappears towards the middle of the shaft. The trochanter tertius and the intertrochanteric line are missing. On the other hand, the femur of femora. The general appearance of these specimens led Pei to believe that they were of human origin and probably belonged to Sinanthropus. A careful study and comparison with human and anthropoid thigh-bones resulted in the conclusion that the femora undoubtedly belong to Sinanthropus.

Femur fragment I was recovered from Level 23 in the western area of the cave, that is to say, Site $J$, from which we already have several fragments of an differs from that of recent man by its stoutnessit seems that the distal end in particular was shorter and broader than in recent man in proportion to the length and breadth of the femur -and by the following specific features: (1) a very pronounced platymery of the entire length of the femur combined with the formation of a distinct pilaster (Figs. $2 b ; 3 a-c$ ) ; (2) a very faint curvature the greatest height of which is located near the lower 
end of the diaphysis (Fig. $2 b$ ); (3) the transversal diameter of the shaft is narrowest near the lower end and gradually increases toward the upper portion (Fig. $1 \mathrm{~b})$; (4) there is a distinct but only faintly developed crista lateralis superior (Fig. 1 b); (5) sections show that the cavity is narrow with rather thick walls, especially the anterior and posterior ones (Fig. $3 d$ ).

Femora of the Neanderthal group (Figs. 1 and 2,c) differ from the femur of Sinanthropus by their greater stoutness, the transversal diameter being narrowest in the middle of the shaft, by a much more pronounced curvature the greatest height of which is also located near the middle of the shaft, and finally by the development of a very strong crista lateralis superior (Fig. $1 \mathrm{c}$ ). To what extent these differences are due to sexual characters is difficult to define. It seems that all the femora available of the Neanderthal group belong to male individuals, whereas I consider the two femora of Sinanthropus as belonging to females on account of the smallness of the two main diameters of the shaft (Table 1, Figs. $1 b$ and $2 b$ ). In addition, femur $M$ comes from the same site as a fragment of a lower jaw ( $M \mathrm{I})$ with two teeth which had been attributed to a female individual.

When compared with the femora of the great apes, those of Sinanthropus represent quite a different type. The general character of the shaft does not conform to any of them. It is of special interest that the Sinanthropus shaft also fails to show any similarity to that of a gibbon, the shaft of the latter being slender as in recent man, with the narrowest part at its middle. It may be deduced from this fact that the frequently stated similarity between femora of gibbon and recent man is of secondary nature and not in the least a fundamental one.

These discoveries of the Sinanthropus femora may also serve to shed some new light upon the problem connected with the Pithe. canthropus femur. Its discoverer, E. Dubois, attributed it as belonging to the same individual or type as that represented by the Pithecanthropus skull cap. The fact that the femur closely resembled one of recent man not only in respect to its general character but also in certain other details was at no time held in doubt and distinctly admitted by Dubois. According to him, one of the most essential differences between the femur of Pithecanthropus and that of recent man should be a pronounced convexity of the upper portion of the popliteal surface of the former.

Femur $M$ of Sinanthropus differs from the Pithecanthropus femur by exactly those features by which it differs also from that of recent man. But with reference to the popliteal surface it shows the same slight convexity as is common in recent man, the platymeric index of this region being $\mathbf{7 6} \cdot 4$ in Sinanthropus against $100^{\circ} 0$ in Pithecanthropus (Table 2). The convexity of the popliteal surface of the Pithecanthropus femur, therefore, cannot be considered a primitive character.

It results from these facts that the Pithecanthropus femur is either one of recent man and with no close relationship to the skull cap, or it really belongs to the latter and thereby testifies that Pithecanthropus represents a much more advanced hominid type than Sinanthropus. I consider the first alternative to be the correct one. As proved by the skulls, both Sinanthropus and Pithecanthropus exhibit in general approximately the same degree of primitiveness. On the other hand, the femur of Sinanthropus reveals that the Pithecanthropus femur, besides other differences, is much too long and too strong for so small a skull.

In a lecture delivered in December 1937 before the Peking Society of Natural History, I pointed out that the character of the then available specimens of

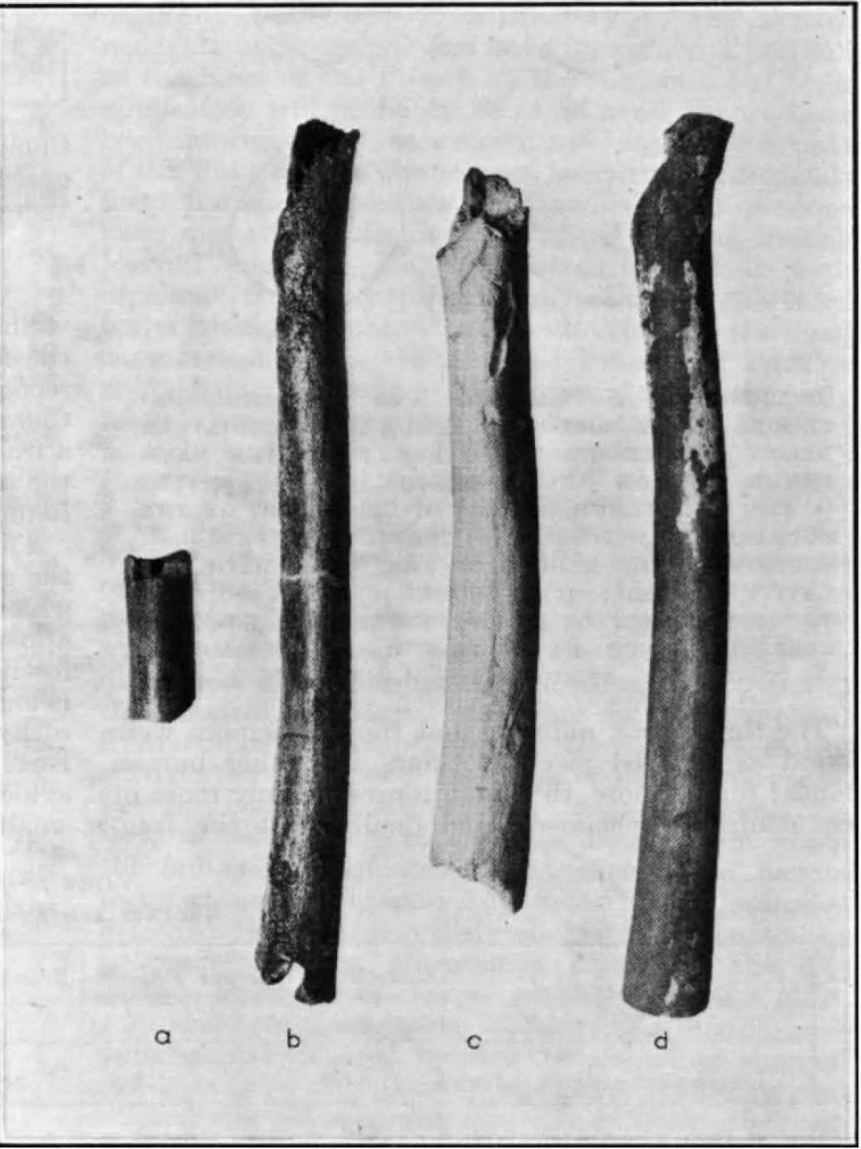

Fig. 2.

ThE SAME FEMORA as IN FIg. 1 VIEWED FROM THE LATERAL SIDE. $(\times 3 / 10$.

extremity bones of Sinanthropus, particularly the collar bone, indicated a more man-like appearance than the skulls and more especially the teeth. On the basis of this, together with the cultural remains, I came to the conclusion that Sinanthropus must have already adopted a completely upright posture and that the approach of the extremity bones to those of man preceded that of skull and teeth. Such a conception has now been confirmed by the discovery of the femur of Sinanthropus and thus leaves no room for doubt that the posture of Sinanthropus was erect. Since the total length of the femur (female) may have approximated $400 \mathrm{~mm}$., the stature of the woman can be estimated to have been about 5 feet $(152 \mathrm{~cm}$.$) , a height which would correspond$ 
to $5 \mathrm{ft} .4 \frac{1}{2}$ in. for male individuals. With such a height, Sinanthropus ranges within the group composed of medium-sized people of to-day. At any rate, it is certain that Sinanthropus was not a pygmy.

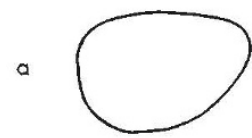

$b$

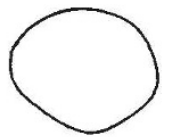

d
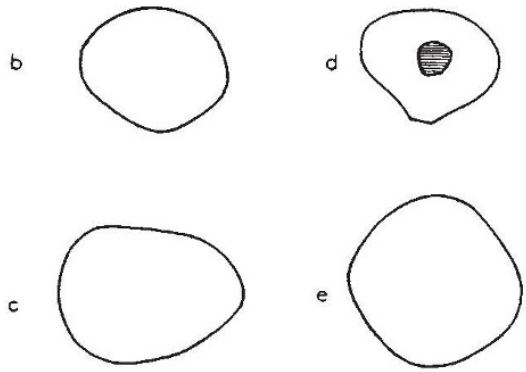

Fig. 3.

Sections of Sinanthropus AND Pithecanthropus FEMORA : (a) Sinanthropus FEMUR $M$, IMMEDIATELY BELOW THE LESSER TROCHANTER; $(b)$ THE SAME FEMUR, SECTION OF THE MIDDLE OF THE SHAFT; (c) THE SAME FEMUR, SECTION OF UPPER PART OF THE SUPRAPATELLAR FOSSA; (d) Sinanthropus FEMUR $J$, SECTION OF THE MIDDLE OF THE SHAFT WITH THE CAVITY MARKED; (e) Pithecanthropus, SECTION OF THE UPPER PART OF THE SUPRAPATELLAR FOSSA IN CORRESPONDENCE TO SECTION $c$ OF Sinanthropus FEMUR $M \cdot\left(\times \frac{1}{2}.\right)$

The three facts, namely, that the two femora were found as isolated pieces without any other human bones; furthermore, that they represent only more or less complete specimens, and finally that the frag- ment of femur $J$ was burnt, point in the same direction as the finds of skull and jaws. All the Sinanthropus bones recovered from Locality 1 of

TABLE 1.

Pringipal Measurements of Femora (IN Mm.).

\begin{tabular}{|c|c|c|c|}
\hline & $\begin{array}{c}\text { Sinan- } \\
\text { thropus } \\
M\end{array}$ & $\begin{array}{c}\text { Sinan- } \\
\text { thropus } \\
\boldsymbol{J}\end{array}$ & \begin{tabular}{l} 
Pithecan- \\
thropus \\
\multirow{3}{*}{}
\end{tabular} \\
\hline $\begin{array}{l}\text { 1. Transversal diameter } \\
\text { (a) upper end } \\
\text { (b) middle } \\
\text { (c) upper popliteal region }\end{array}$ & $\begin{array}{l}34 \cdot 3 \\
29 \cdot 0 \\
36 \cdot 0\end{array}$ & $\overrightarrow{27 \cdot 3}$ & $\begin{array}{l}34 \cdot 6 ? \\
28 \cdot 0 \\
34 \cdot 3\end{array}$ \\
\hline $\begin{array}{l}\text { 2. Sagittal diameter } \\
\text { (a) upper end } \\
\text { (b) middle } \\
\text { (c) upper popliteal region }\end{array}$ & $\begin{array}{l}22 \cdot 1 \\
24 \cdot 1 \\
27 \cdot 5\end{array}$ & $2 \overline{2 \cdot 6}$ & $\begin{array}{l}31 \cdot 0 \\
29 \cdot 0 \\
34 \cdot 3\end{array}$ \\
\hline 3. Circumference (middle of & $88 \cdot 0$ & 77.0 & 89.0 \\
\hline
\end{tabular}

Choukoutien had received the same treatment as the game which Sinanthropus hunted. This hominid, therefore, was a cannibal.

February 10.

\section{The Humerus}

Shortly after the discovery of two fragments of the femur of Sinanthropus pekinensis, Dr. W. C. Pei recognized, among the material of Locality 1 of Choukoutien now in preparation in the Laboratory, a fragment of a humerus. This fragment comes from the same level (23) as the femur fragment $J$, but was found about $13 \mathrm{~m}$. away from the latter.

The fragment is strongly fossilized and represents the greater part of a left diaphysis the total length of which is $187 \mathrm{~mm}$. Both end parts are missing and apparently broken away previous to the process of fossilization. There is no doubt that the humerus belongs to Sinanthropus, its general appearance being rather similar to that of Neanderthal or recent man. But at the same time conspicuous differences are evident, namely, the diaphysis is very slender, the smallest circumference being only $60 \mathrm{~mm}$. and the

TABLE 2.

INDEXES AND ANGLES.

\begin{tabular}{|c|c|c|c|c|c|c|c|c|c|}
\hline & $\begin{array}{c}\text { Sinanthropus } \\
M \\
+\end{array}$ & $\begin{array}{c}\text { Sinan- } \\
\text { thropus } \\
J \\
\text { o } \\
\end{array}$ & $\begin{array}{c}\text { Pithecan- } \\
\text { thropus } \\
\delta\end{array}$ & $\begin{array}{c}\text { Neanderthal } \\
\delta\end{array}$ & $\begin{array}{l}\text { Recent } \\
\text { Man }\end{array}$ & Gorilla & $\begin{array}{l}\text { Chim- } \\
\text { panzee }\end{array}$ & Orang & Gibbon \\
\hline 1. Length-circumference index & $22 \cdot 0(?)$ & - & $19 \cdot 5$ & $22 \cdot 3$ & $17 \cdot 5-21 \cdot 3$ & $\begin{array}{c}\stackrel{9}{9} \\
31 \cdot 0\end{array}$ & $\begin{array}{c}9 \\
33 \cdot 7\end{array}$ & $30^{7} \cdot 3$ & $\begin{array}{l}8.0 \\
18 \cdot 1 \\
1\end{array}$ \\
\hline 2. Robusticity index & $17 \cdot 3(?)$ & - & $12 \cdot 5$ & $13 \cdot 5-14 \cdot 1$ & $11 \cdot 7-12 \cdot 5$ & $17 \cdot 2$ & $15 \cdot 7$ & $\frac{0}{15} \cdot \frac{9}{7}$ & $10 \cdot 8$ \\
\hline 3. Pilastric Index & $84 \cdot 0$ & $84 \cdot 0$ & $103 \cdot 8$ & $99-100 \cdot 5$ & $100-122$ & $\begin{array}{r}0.9 \\
75 \cdot 4 \\
\end{array}$ & $\begin{array}{l}0.9 \\
84 \cdot 6\end{array}$ & $78 \cdot 5$ & $97 \cdot 1$ \\
\hline $\begin{array}{l}\text { 4. Platymeric index : } \\
\text { (a) upper end } \\
\text { (b) popliteal region }\end{array}$ & $\begin{array}{l}64 \cdot 5 \\
76 \cdot 4 \\
\end{array}$ & - & $\begin{array}{c}89 \cdot 8 ? \\
\text { or more } \\
100 \cdot 0\end{array}$ & $\begin{array}{c}69 \cdot 8-85 \cdot 3 \\
-\end{array}$ & $\begin{array}{c}6 \\
64 \cdot 3-85 \cdot 9 \\
-\end{array}$ & $\begin{array}{c}6 \quad 9 \\
81 \cdot 0 \\
9 \\
66 \cdot 3\end{array}$ & $\begin{array}{l}0 \% \\
82 \cdot 8 \\
80 \cdot 3\end{array}$ & $\begin{array}{l}5 \\
71 \cdot 2 \\
66 \cdot 9\end{array}$ & $\begin{array}{c}82 \cdot 8 \\
-\end{array}$ \\
\hline $\begin{array}{l}\text { 5. Index of the curvature } \\
\text { (after Ried) }\end{array}$ & $2 \cdot 03$ & 一 & $2 \cdot 15$ & $5 \cdot 0-5 \cdot 5$ & $\begin{array}{c}3 \cdot 3 \\
(1 \cdot 8-5 \cdot 0)\end{array}$ & $2 \cdot 73$ & $2 \cdot 88$ & $1 \stackrel{0}{t} \cdot 86$ & - \\
\hline $\begin{array}{l}\text { 6. Indexes of the position of } \\
\text { the vertex of the curvature } \\
\text { (after Ried) } \\
\text { (a) Index I } \\
\text { (b) Index II }\end{array}$ & $\begin{array}{l}35 \cdot 9 \\
37 \cdot 5\end{array}$ & $\overline{-}$ & $\begin{array}{l}47 \cdot 2 \\
46 \cdot 3\end{array}$ & $43-\overline{-45} \cdot 1$ & $\overline{56 \cdot 0}$ & $\begin{array}{l}\frac{9}{7} \cdot 5 \\
48 \cdot 7\end{array}$ & $\begin{array}{l}5{ }^{*} \cdot 3 \\
52 \cdot 9\end{array}$ & $\begin{array}{l}50 \\
55 \cdot 8 \\
50 \cdot 4\end{array}$ & 二 \\
\hline $\begin{array}{l}\text { 7. Index of the robustness of } \\
\text { the wall } \\
\text { (a) ant. wall } \\
\text { (b) post. wall } \\
\text { (c) lat. wall } \\
\text { (d) med. wall }\end{array}$ & $\begin{array}{l}37 \cdot 1 \\
37 \cdot 1 \\
39 \cdot 4 \\
30 \cdot 8\end{array}$ & $\begin{array}{l}30 \cdot 1 \\
40 \cdot 7 \\
39 \cdot 7 \\
36 \cdot 3\end{array}$ & - & - & $\begin{array}{c}9 \\
23 \cdot 9 \\
33 \cdot 4 \\
34 \cdot 2 \\
24 \cdot 7\end{array}$ & & & & \\
\hline 8. Collar angle & circa $110^{\circ}$ & - & $123^{\circ}$ & $115-120^{\circ}$ & $121-133^{\circ}$ & $115^{\circ}$ & $120^{\circ}$ & $130^{\circ}$ & $130^{\circ}$ \\
\hline
\end{tabular}


circumference immediately below the surgical neck only $71 \mathrm{~mm}$. The markings of muscle insertion, how ever, are surprisingly well pronounced, especially those of the deltoid and pectoralis major. The tuberositas deltoidea continues in a ridge-like projecting crest, the total length of which is $15 \mathrm{~mm}$. The crista tubereuli majoris is likewise strongly developed, and there is also a well-circumscribed tuberositas corresponding to the attachment for the $\mathrm{m}$. teres major. The sulcus radialis is also rather distinct, indicating a well-developed torsion of the humerus. In addition, the borders represent sharply demarcated edges, so that a cross-section of the upper part shows an almost quadrangular outline, while one of the lower parts beyond the end of the tuberositas deltoidea has the form of a real triangle. These features combined give the humerus of Sinanthropus a specific character.

In view of the deficiency of the fragment, it is not possible to determine with any degree of certainty the original length of the humerus. On the basis of the form and length of the fragment, however, the total length may be estimated to have been at least $310 \mathrm{~mm}$. Despite the strong development of the muscle markings and the edge-like character of the borders, I consider the humerus as belonging to a female individual on account of its extraordinary slenderness.

As is evident from this brief description, the humerus of Sinanthropus does not show any special similarity to the humeri of great apes. It is specifically human in its entire appearance. The strong development of the muscle markings, especially those of the deltoid, pectoralis major and teres major and the edge-like character of the borders indicate that the upper limb was used in the same manner as in recent man, that is to say, it was already completely freed from locomotion. So far as is possible to deduce from the fragments of femur and humerus, their proportion in length may have been the same in principle as in recent man.

The view I have recently put forward that the skeleton of Sinanthropus approached that of man much closer than the brain case and the teeth do, receives additional support by the discovery of the humerus.

February 17.

\section{Science News a Century Ago}

\section{Medical Missions}

THE March issue of 1838 of the Gentleman's Magazine contains the following information : "The first evening meeting of the Royal College of Physicians was held in Trafalgar Square on February 5, and a more crowded audience of members and visitors has, perhaps, never occurred. Amongst the latter were his Royal Highness, the Duke of Cambridge, the Duke of Wellington, the Archbishop of Canterbury, the Bishop of London, the Chief Justice of the Common Pleas, Sir Lancelot Shadwell, Sir Robert Peel, etc., etc. The President, Sir Henry Halford, read a paper recommending in eloquent terms the union of medical with theological knowledge in the attainments of missionaries to the eastern nations, and pointing out the great advantages which would result from such a connexion. He observed that great progress had been made in China and the other Asiatic countries in the healing art by the energy of the missionaries, and that vaccination and other European improvements in medicine had been introduced by their instrumentality. Sir Henry also took a view of the state of national physiology and pathology as understood in China, and pointed out the absurdities of the system of the natives."

\section{English Physicians in France}

THE issue of the Lancet of March 31, 1838, contains the following information: "The affair of the English physicians in France (prosecution for unauthorised practice at Boulogne) has terminated in the condemnation of Drs. Carter, Scott, Shuter, Allatt and Galbraith to the payment of a trifling sum, which, however, is equivalent to an interdiction from practising medicine in France. This decree has naturally been very unsatisfactory to the British residents at Boulogne who have forwarded a petition to the King of the French on the subject; but their application will probably be of no avail, for we have been informed that, at a recent meeting of the Senate of the University of France, not less than ten demands from foreign physicians for permission to practise have met with a decided refusal. A leading French journal suggests that physicians furnished with diplomas from any foreign university or chartered body should be immediately admitted to the final examination (at a reduced fee) before the Faculty of Medicine of Paris. This appears to be the only feasible way of compromising the matter."

\section{Faraday's Researches in Electricity}

ON April 5, 1838, at a meeting of the Royal Society, the reading of Faraday's Thirteenth Series of "Experimental Researches in Electricity" was resumed and concluded. "The author, in this paper," said the Athenceum, "pursues the inquiry into the differences observable in the luminous phenomena of the electric discharge, according as they proceed from bodies in the positive or the negative states, with a view to discover the cause of those differences. For the convenience of description, he employs the term inductric to designate those bodies from which the induction originates, and inducteous to denote those whose electric state is disturbed by this inductive action. . . . He also directed his attention to the peculiar luminous phenomena attending the dis. ruptive electrical discharge, which he terms a glow, ... and the convective, or carrying dischargenamely that effected by the translation of charged particles from one place to another. He lastly considered electric currents, not only in their effects on the bodies they traverse, but also in their collateral influences, as producing inductive and magnetical phenomena. He announced his intention shortly to give further views he entertains concerning the nature of electric forces and electric excitation in connexion with the theory he had advanced."

\section{The Ant-tree of Guiana}

At a meeting of the Botanical Society on April 6, 1838 , the Secretary read a paper from R. H. Schomburgk (still in British Guiana) on the Triplaris Americana, the ant-tree of Guiana. The trunk, the letter said, is slender, grows up straight, and its erect branches form a pyramid. It is unisexual ; and the flowers of both sexes are insignificant : those of the male last only for a few days, when they dry up; this is likewise the case with the petals of the female. The segments of the calix, however, continue to grow from green to white and vermilion, and become so attenuated that the branched nerves are easily 